\title{
The Complexity of Interpreting Plateau Pressure in ARDS
}

In the early years of lung-protective ventilation, it was thought that limiting plateau pressure $\left(\mathrm{P}_{\text {plat }}\right)$, a signifier of alveolar stress, was important for improving survival in patients with ARDS. However, there were no clinical data and no agreement on the limit. A 1993 consensus conference recommended that $\mathrm{P}_{\text {plat }}$ be limited to $35 \mathrm{~cm} \mathrm{H}_{2} \mathrm{O}{ }^{1}$ This was based on the assumption that, despite heterogeneous lung injury, it was probably safe to ventilate the lungs at or below total lung capacity, which would correspond to a $\mathrm{P}_{\text {plat }}$ of $30-35 \mathrm{~cm} \mathrm{H}_{2} \mathrm{O} .{ }^{2}$ Others suggested that a more liberal $\mathrm{P}_{\text {plat }}$ limit of $40-50 \mathrm{~cm} \mathrm{H}_{2} \mathrm{O}$ might be reasonable in severe ARDS. ${ }^{3-5}$

It is astonishing to witness the change that has occurred in our approach to targeting $\mathrm{P}_{\text {plat }}$ since the seminal ARMA trial. ${ }^{6}$ Since then, a tidal volume $\left(\mathrm{V}_{\mathrm{T}}\right)$ targeted between 4 and $8 \mathrm{~mL} / \mathrm{kg}$ is generally used to keep $\mathrm{P}_{\text {plat }}$ at $\leq 30 \mathrm{~cm} \mathrm{H}_{2} \mathrm{O}$. Post-ARMA studies suggest that not only does lung-protective ventilation decrease the likelihood of developing ARDS, ${ }^{7}$ but also that there may not be an unambiguously safe $\mathrm{P}_{\text {plat }}$ in patients with established ARDS. 8,9

The study by Chan et $\mathrm{a}^{10}$ in this issue of RespiRATORY CARE specifically examines the importance of limiting $P_{\text {plat }}$ in patients with sepsis. Their primary finding was that during the first $24 \mathrm{~h}$ of mechanical ventilation, the mean $\mathrm{P}_{\text {plat }}$ was higher in nonsurvivors despite being $<30 \mathrm{~cm}$ $\mathrm{H}_{2} \mathrm{O}$. Moreover, at $24 \mathrm{~h}$, those subjects with a $\mathrm{P}_{\text {plat }}$ of $>25 \mathrm{~cm} \mathrm{H}_{2} \mathrm{O}$ had nearly a 3-fold higher mortality risk. These findings are similar to those in subjects with established ARDS, wherein despite achieving a $\mathrm{V}_{\mathrm{T}}$ of $6 \mathrm{~mL} / \mathrm{kg}$, subjects with a $\mathrm{P}_{\text {plat }}$ of $28-30 \mathrm{~cm} \mathrm{H}_{2} \mathrm{O}$ had higher regional pulmonary hyperinflation and pro-inflammatory mediator release associated with higher mortality compared with subjects with a $\mathrm{P}_{\text {plat }}$ of $25-26 \mathrm{~cm} \mathrm{H}_{2} \mathrm{O} .{ }^{9}$ We also observed a trend toward higher mortality during lung-protective ventilation related to a mean $\mathrm{P}_{\text {plat }}$ of $\sim 25 \mathrm{~cm} \mathrm{H}_{2} \mathrm{O}$ versus 27-29 $\mathrm{cm} \mathrm{H}_{2} \mathrm{O}$ during the first week of ARDS. ${ }^{11,12}$ When viewed together, these studies suggest that just achieving

\footnotetext{
Mr Kallet has disclosed no conflicts of interest.

Correspondence: Richard H Kallet MSc RRT FAARC, Department of Anesthesia, University of California, San Francisco, at San Francisco General Hospital, NH:GA-2, 1001 Potrero Ave, San Francisco, CA 94110. E-mail: rich.kallet@ucsf.edu.
}

DOI: $10.4187 /$ respcare. 03727 a $\mathrm{P}_{\text {plat }}$ of $\leq 30 \mathrm{~cm} \mathrm{H}_{2} \mathrm{O}$ may not be sufficient to optimize survival from ARDS or sepsis.

An intriguing finding of Chan et $\mathrm{al}^{10}$ was that nonsurvivors were actually managed more closely to lung-protective ventilation goals in terms of mean $\mathrm{V}_{\mathrm{T}}$ and PEEP compared with survivors. Nonsurvivors were sicker as judged by significantly higher Acute Physiology and Chronic Health Evaluation II scores, larger positive fluid balance, and lower respiratory system compliance. Thus the interpretation of what the higher $\mathrm{P}_{\text {plat }}$ in nonsurvivors signified in this study is not altogether clear.

Both $\mathrm{P}_{\text {plat }}$ and respiratory system compliance are convenient but crude surrogates for lung stress. As these variables are system measurements (ie, lung and chest wall compliance exists in series), their physiologic validity in terms of lung stress rests upon the assumption that chest wall compliance remains normal. In ARDS, that assumption is precarious, as most studies examining pulmonary mechanics reported that chest wall compliance in ARDS was reduced by $50-80 \%{ }^{13}$

See the Original Study on Page 12

This is particularly relevant when managing ARDS associated with systemic capillary leak (eg, sepsis, trauma, burns). These patients often require aggressive fluid resuscitation to maintain systemic perfusion, which, in consequence, aggravates fluid extravasation into the extracellular compartment, thus reducing both lung and chest wall compliance. Mortality in critically ill patients (including those with sepsis or ARDS) is associated with increased extravascular lung water ${ }^{14,15}$ and impaired alveolar fluid clearance. ${ }^{16}$ Conservative fluid management has been shown to reduce mortality ${ }^{17}$ or to be associated with a trend toward reduced mortality in ARDS. ${ }^{18}$

Furthermore, recent research into ventilator-associated lung injury has uncovered an important contribution from altered pulmonary hemodynamics. In brief, the combination of elevated pulmonary arterial pressures (transmitted to extra-alveolar vessels) with high inflation pressures amplifies transmicrovascular pressures sufficient to cause stress fractures in the pulmonary endothelium. The critical pressure gradient needed to induce capillary stress failure is likely influenced by the deleterious effects of surfactant depletion and inflammation on the integrity of the base- 


\section{The Complexity of Interpreting Plateau Pressure in ARDS}

ment membrane. ${ }^{19}$ Thus, the interpretation of controlling $\mathrm{P}_{\text {plat }}$ in ARDS is highly contextualized and includes ambiguities in a popular classification scheme.

It is conceptually convenient to designate ARDS as either direct (pulmonary) injury caused by pneumonia, aspiration, contusion, or inhalation injury or indirect (extrapulmonary or blood-borne) injury caused by sepsis, non-thoracic trauma, pancreatitis, or transfusion reactions. These distinctions in etiology are conjoined with observed differences in pulmonary mechanics attributed to the underlying pathogenesis. ${ }^{20}$ In brief, direct injury is characterized by alveolar consolidation, which ostensibly occurs with relatively lower potentially recruitable lung tissue. In contrast, indirect injury appears more amenable to recruitment because it is characterized by congestive and compressive atelectasis.

This scheme has been useful in providing a general guide for applying higher PEEP and recruitment maneuvers in different etiologies of ARDS. Unfortunately, it is also likely to be an oversimplification of a complex problem. Pneumonia is the leading cause of both ARDS and sepsis (accounting for $\sim 50 \%$ of cases), ${ }^{21}$ thus considerably blurring an otherwise elegant classification scheme. More importantly, on average, the alveolar-capillary membrane is only $0.6 \mu \mathrm{m}$ thick, ${ }^{22}$ making it implausible that the inflammatory response to parenchymal injury would result in such distinct manifestations depending upon which side of the barrier was initially injured.

The major distinction between pulmonary and extrapulmonary ARDS is the effect of abdominal distention on chest wall compliance. ${ }^{20,23}$ Aggressive volume infusion tends to cause abdominal distention, resulting in decreased chest wall compliance and lung compression. ${ }^{24}$ Patients with intra-abdominal injuries, pancreatitis, extensive burns, or sepsis would more likely exhibit the mechanical problems we classify as extrapulmonary ARDS. However, we have observed obese patients with ARDS (both from H1N1 and bacterial pneumonia) whose response to high PEEP and recruitment maneuvers was indistinguishable from that of similarly treated patients with so-called extrapulmonary ARDS.

Furthermore, these ambiguities lend support for measuring esophageal pressure $\left(\mathrm{P}_{\mathrm{es}}\right)$ to estimate end-inspiratory and end-expiratory transpulmonary pressure in ARDS. This would likely improve the implementation of lungprotective ventilation (at least in the subset of patients suspected of having reduced chest wall compliance), as it would allow for the estimation of gross transpulmonary pressure when setting both $\mathrm{V}_{\mathrm{T}}$ and PEEP $\left(\mathrm{P}_{\text {plat }}-\mathrm{P}_{\mathrm{es}}\right.$ end inspiration; PEEP $-\mathrm{P}_{\mathrm{es}}$ end expiration). A further refinement would be integrating dead-space measurements with transpulmonary pressure measurements, as the combination may help in both identifying and balancing lung recruitment and overdistention. However, as others have pointed out, ${ }^{25}$ measuring $\mathrm{P}_{\mathrm{es}}$ has important limitations. It requires relatively extensive knowledge of pulmonary mechanics, as well as bedside experience to master its ambiguities.

Notwithstanding these challenges, the importance of measuring chest mechanics in ARDS will likely gain importance and should provide professional growth opportunities for respiratory therapists. For now, the take-home message for managing ARDS or sepsis is that, when feasible, $\mathrm{V}_{\mathrm{T}}$ should be targeted to achieve a $\mathrm{P}_{\text {plat }}$ goal of $25 \mathrm{~cm} \mathrm{H}_{2} \mathrm{O}$.

\section{Richard H Kallet MSc RRT FAARC Respiratory Care Services Department of Anesthesia University of California, San Francisco, at San Francisco General Hospital San Francisco, California}

\section{REFERENCES}

1. Slutsky AS. Consensus conference on mechanical ventilation-January 28-30, 1993 at Northbrook, Illinois, USA. Part I. European Society of Intensive Care Medicine, the ACCP and the SCCM. Intensive Care Med 1994;20(1):64-79.

2. Hubmayr RD. Setting the ventilator. In Tobin MJ, editor. Principles and practice of mechanical ventilation. New York: McGraw-Hill; 1994:191-206.

3. Marcy TW, Marini JJ. Inverse ratio ventilation in ARDS. Chest 1991;100(2):494-504.

4. Kollef MH, Schuster DP. The acute respiratory distress syndrome. N Engl J Med 1995;332(1):27-37.

5. Hudson LD. Protective ventilation for patients with acute respiratory distress syndrome. N Engl J Med 1998;338(6):385-387.

6. The Acute Respiratory Distress Syndrome Network. Ventilation with lower tidal volumes as compared with traditional tidal volumes for acute lung injury and the acute respiratory distress syndrome. N Engl J Med 2000;342(18):1301-1308.

7. Fuller BM, Mohr NM, Drewry AM, Carpenter CR. Lower tidal volume at initiation of mechanical ventilation may reduce progression to acute respiratory distress syndrome: a systematic review. Crit Care 2013;17(1):R11.

8. Hager DN, Krishnan JA, Hayden DL, Brower RG, ARDS Clinical Trials Network. Tidal volume reduction in patients with acute lung injury when plateau pressures are not high. Am J Respir Crit Care Med 2005;172(10):1241-1245.

9. Terragni PP, Rosboch G, Tealdi A, Corno E, Menaldo E, Davini O, et al. Tidal hyperinflation during low tidal volume ventilation in acute respiratory distress syndrome. Am J Respir Crit Care Med 2007;175(2):160-166.

10. Chan MC, Tseng JS, Chiu JT, Hsu KH, Shih SJ, Yi CY, et al. Prognostic value of plateau pressure below $30 \mathrm{~cm} \mathrm{H}_{2} \mathrm{O}$ in septic patients with acute respiratory failure. Respir Care 2015;60(1):1220.

11. Seeley E, McAuley DF, Eisner M, Miletin M, Matthay MA, Kallet RH. Respiratory system compliance and severity of hypoxemia as predictors of outcome in the acute respiratory distress syndrome. Thorax 2008;63(11):994-998.

12. Seeley EJ, McAuley DF, Eisner M, Miletin M, Zhou H, Matthay MA, Kallet RH. Decreased respiratory system compliance on day 6 


\section{The Complexity of Interpreting Plateau Pressure in ARDS}

of mechanical ventilation is a predictor of death in patients with established acute lung injury. Respir Res 2011;12:52.

13. Kallet RH, Katz JA. Respiratory system mechanics in acute respiratory distress syndrome. Respir Care Clin N Am 2003;9(3):297319.

14. Schuller D, Mitchell JP, Calandrino FS, Schuster DP. Fluid balance during pulmonary edema. Is fluid gain a marker or cause of poor outcome? Chest 1991;100(4):1068-1075.

15. Sakka SG, Klein M, Reinhart K, Meier-Hellmann A. Prognostic value of extravascular lung water in critically ill patients. Chest 2002;122(6):2080-2086.

16. Ware LB, Matthay MA. Alveolar fluid clearance is impaired in the majority of patients with acute lung injury and the acute respiratory distress syndrome. Am J Respir Crit Care Med 2001;163(6):13761383.

17. Humphrey H, Hall J, Sznajder I, Silverstein M, Wood L. Improved survival in ARDS patients associated with a reduction in pulmonary capillary wedge pressure. Chest 1990;97(5):1176-1180.

18. National Heart, Lung, and Blood Institute Acute Respiratory Distress Syndrome (ARDS) Clinical Trials Network, Wiedemann HP, Wheeler AP, Bernard GR, Thompson BT, Hayden D, et al. Comparison of two fluid-management strategies in acute lung injury. N Engl J Med 2006;354(24):2564-2575.

19. Marini JJ. Microvasculature in ventilator-induced lung injury: target or cause? Minerva Anestesiol 2004;70(4):167-173.

20. Gattinoni L, Pelosi P, Suter PM, Pedoto A, Vercesi P, Lissoni A. Acute respiratory distress syndrome caused by pulmonary and extrapulmonary disease. Different syndrome? Am J Respir Crit Care Med 1998;158(1):3-11

21. Angus DC, van der Poll T. Severe sepsis and septic shock. N Engl J Med 2013;369(9):840-851.

22. Hall JE. Guyton and Hall textbook of medical physiology, 12th edition. Philadelphia: Saunders; 2010:451-464.

23. Ranieri VM, Brienza N, Santostasi S, Puntillo F, Mascia L, Vitale N, et al. Impairment of lung and chest wall mechanics in patients with acute respiratory distress syndrome. Role of abdominal distension. Am J Respir Crit Care Med 1997;156(4):1082-1091.

24. Mutoh T, Lamm WJ, Embree LJ, Hildebrandt J, Albert RK. Volume infusion produces abdominal distension, lung compression, and chest wall stiffening in pigs. J Appl Physiol 199;72(2):575-582.

25. Richard JC, Marini JJ. Transpulmonary pressure as a surrogate of plateau pressure for lung protective strategy: not perfect but more physiologic. Intensive Care Med 2012;38(3):339-341. 